\title{
Phytofabrication and characterization of monodisperse copper oxide nanoparticles using Albizia lebbeck leaf extract
}

\author{
G. Jayakumarai $\cdot$ C. Gokulpriya $\cdot$ R. Sudhapriya $\cdot$ \\ G. Sharmila $\cdot$ C. Muthukumaran
}

Received: 30 December 2014/ Accepted: 16 January 2015/Published online: 31 January 2015

(C) The Author(s) 2015. This article is published with open access at Springerlink.com

\begin{abstract}
Simple effective and rapid approach for the green synthesis of copper oxide nanoparticles (CONPs) using of Albizia lebbeck leaf extract was investigated in this study. Various instrumental techniques were adopted to characterize the synthesized CONPs, viz. UV-Vis spectroscopy, SEM, TEM, EDS and XRD. The synthesized CONPs were found to be spherical in shape and size less than $100 \mathrm{~nm}$. It could be concluded that A. lebbeck leaf extract can be used as a cheap and effective reducing agent for CONPs production in large scale.
\end{abstract}

Keywords Nanoparticles - Copper oxide - Albizia lebbeck · Green synthesis · Electron microscopy

\section{Introduction}

Metal nanoparticles gained much interest in recent years in the nanotechnology field due to their remarkable properties such as optical, magnetic and catalytic activity (Bhattacharya and Gupta 2005). Metal nanoparticles finding promising applications in nanosensors, optoelectronics, nanodevices, absorbents, information storage, etc. (Harne et al. 2012). In literature, silver and gold nanoparticles are extensively studied because of their high conductivity and non-oxidizing nature but synthesis of copper and copper-based nanoparticles are limited (Abboud et al. 2014; Sankar et al. 2014; Gunalan et al. 2012; Lee et al. 2011). Copper oxide (CuO) nanoparticles are of

G. Jayakumarai · C. Gokulpriya · R. Sudhapriya

G. Sharmila $\cdot$ C. Muthukumaran $(\bowtie)$

Department of Industrial Biotechnology, Government College of

Technology, Coimbatore 641013, Tamilnadu, India

e-mail: biopearl1981@gmail.com significant technological interest and have attracted more attention due to their high conductivity and low cost. $\mathrm{CuO}$ nanoparticles are used in superconductors, gas sensors, magneto resistance materials, lubricants, lithography, dye sensitized solar cells and nanostructure composites preparation ( $\mathrm{Li}$ et al. 2008; Kruis et al. 1998; Cheon et al. 2012; Tarasov et al. 2002; Baik et al. 2000). Biological applications of $\mathrm{CuO}$ nanoparticles include as an antimicrobial, anti-fouling, anti-biotic, anti-fungal agent when added to textiles (Abramov et al. 2009) and also used as biocidal agent in pesticide production (De Oliveira-Filho et al. 2004). Copper oxide nanoparticles can be synthesized by various methods like electrochemical, sonochemical, chemical reduction, microwave irradiations, etc. (Mandke and Pathan 2012; Dang et al. 2011; Zhao et al. 2004). Use of toxic chemicals as reducing and capping agents in chemical synthesis restricts the use of $\mathrm{CuO}$ nanoparticles in biological applications and also discharge of wastes may lead to environmental pollution. With increasing awareness in green chemistry, the scientific community has been focused on development of ecofriendly and biocompatible nanoparticle synthesis methodologies (Tsibakhashvil et al. 2010). Microorganisms, plants and enzymes are employed as environmental benign materials for synthesis of biocompatible, non-toxic synthesis of metal nanoparticles (Abboud et al. 2014; Tsibakhashvil et al. 2010; Augustine et al. 2014; Vetchinkina et al.2014). Synthesis of metal nanoparticles using plant extracts was found valuable process as compared to microbes due to several advantages like simple process, easily available, safe to handle and easily scaled up (Kouvaris et al. 2012; Vanaja and Annadurai 2012). Reduction rate and stabilization of nanoparticles can be increased by the presence of various phytochemicals in plant extract which mediate the nanoparticle synthesis and 
can act as capping and reducing agents (Rashmi and Preeti 2009). Studies on biological synthesis of CONPs using plant are limited in the literature and no report is available for Albizia lebbeck leaf extract. The present study attempts to utilize for the first time A. lebbeck leaf extract as reducing agent to synthesis CONPs. Characterization of synthesized CONPs was done by UV-Vis spectroscopy, SEM, EDS and TEM analysis.

\section{Experimental}

Preparation of A. lebbeck aqueous leaf extract

Fresh leaves of A. lebbeck were collected from Government College of Technology campus, Coimbatore. The leaves were surface cleaned with double distilled water, shade dried for a week and powdered using a kitchen blender. $5 \mathrm{~g}$ of leaf powder was mixed with $50 \mathrm{~mL}$ of double distilled water and kept in a water bath at $60{ }^{\circ} \mathrm{C}$ for $10 \mathrm{~min}$. The extract was filtered by using Whatman No. 1 filter paper and stored at $4{ }^{\circ} \mathrm{C}$ for further use.

\section{Green synthesis of CONPs}

$10 \mathrm{~mL}$ of $A$. lebbeck aqueous extract was mixed with $90 \mathrm{~mL}$ of copper sulphate $(1 \mathrm{mM})$ solution in an Erlenmeyer flask incubated in the dark at $37{ }^{\circ} \mathrm{C}$ for synthesis of CONPs. A control setup was also maintained without $A$. lebbeck leaf extract. The formation of CONPs was confirmed by colour changes from pale yellow to brown.

\section{Characterization of CONPs}

UV-Vis spectroscopy analysis

The reaction progress for the formation of CONPs using $A$. lebbeck leaf extract was monitored by visual colour change and UV-Vis spectral scanning. Surface plasmon resonance (SPR) of CONPs was characterized by using UV-Vis spectrophotometer (Hach DR 5000) at the resolution of $1 \mathrm{~nm}$ from 300 to $700 \mathrm{~nm}$. The plant extract was used as control.

SEM and EDS analysis

The sample was prepared with a drop of colloidal solution of nano copper oxide on a carbon-coated copper grid and completely dried by vacuum desiccator. SEM (FEI Qunata 250, Czech Republic) instrument at accelerating voltage of $30 \mathrm{kV}$ equipped with EDS was used.

\section{TEM analysis}

A drop of aqueous CONPs sample was loaded on the carbon-coated copper grid which was allowed to dry for an hour. The size and shape of CONPs from A. lebbeck were determined from TEM images.

XRD analysis

CONPs were dried and the powdered sample was used for $\mathrm{X}$-ray diffraction (XRD) analysis. The XRD analysis was
Fig. 1 UV-Vis spectra of CONPs synthesized with $A$. lebbeck leaf extract

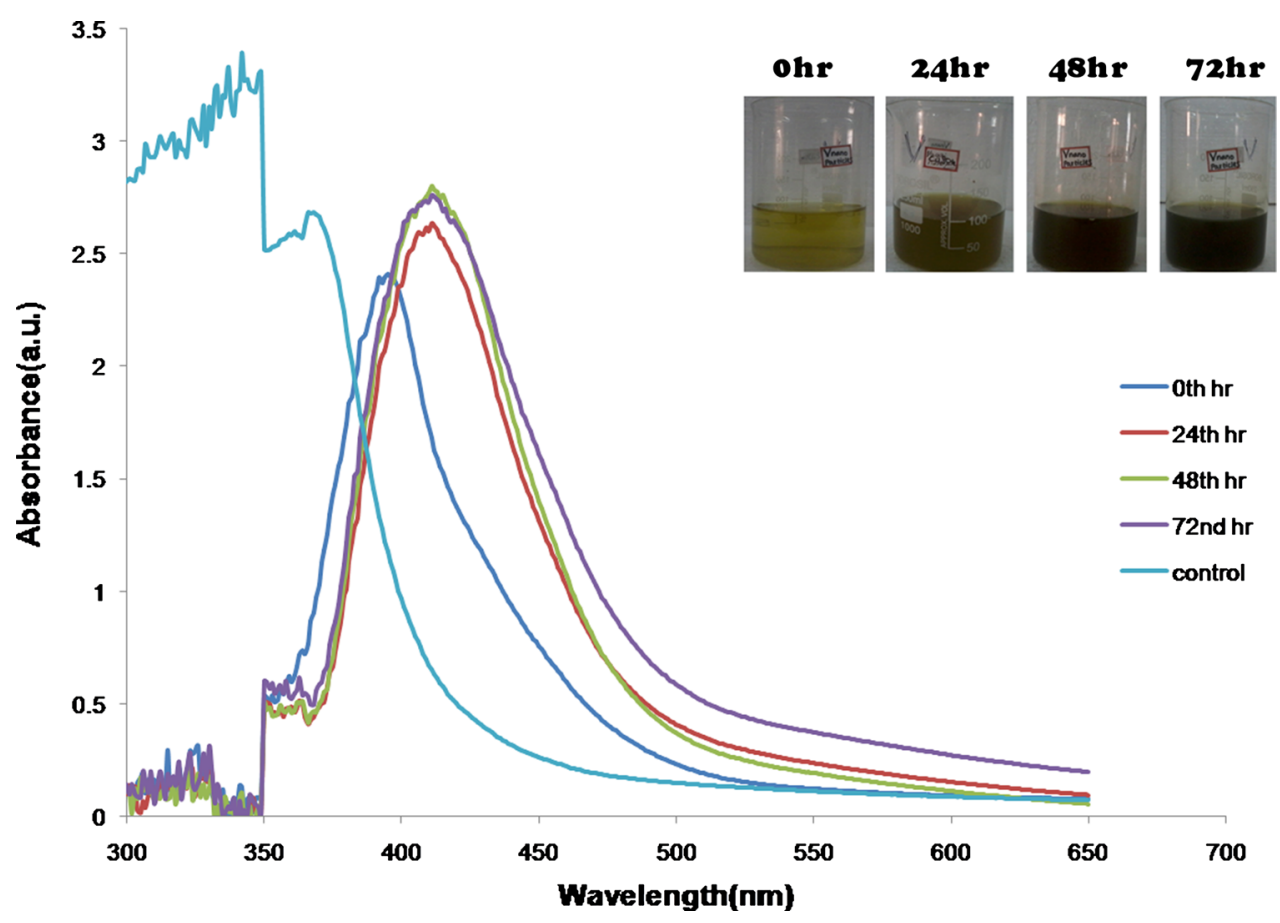


performed by X'Pert Pro A Analytical X-ray diffractometer using $\mathrm{Cu} \mathrm{K} \alpha$ radiation in the range of $10^{\circ}-80^{\circ}$ at $3 \mathrm{~kW}$.

\section{Results and discussion}

In the present study, A. lebbeck leaf extract was used as reducing agent for synthesis of CONPs. A. lebbeck leaf extract was mixed with copper sulphate solution and the reaction mixture starts colour change after $24 \mathrm{~h}$ of incubation (Fig. 1). Colour change observed in the reaction mixture confirmed the formation of CONPs. UV-Vis spectroscopy is a valuable tool to study the SPR of synthesized nanoparticles. The UV-Vis spectra of CONPs synthesized using A. lebbeck showing absorption peak maxima at $413 \mathrm{~nm}$ and found to be characteristic peak of CONPs (Fig. 1). Colour change was due to the excitation of SPR of CONPs (Mulvaney 1996). According to Mei's theory, the shape of the synthesized nanoparticle is spherical if a single sharp absorbance peak observed in the UV-Vis spectrum (Mie 1908), and in our study presence of the single peak confirmed that synthesized CONPs were spherical in shape.
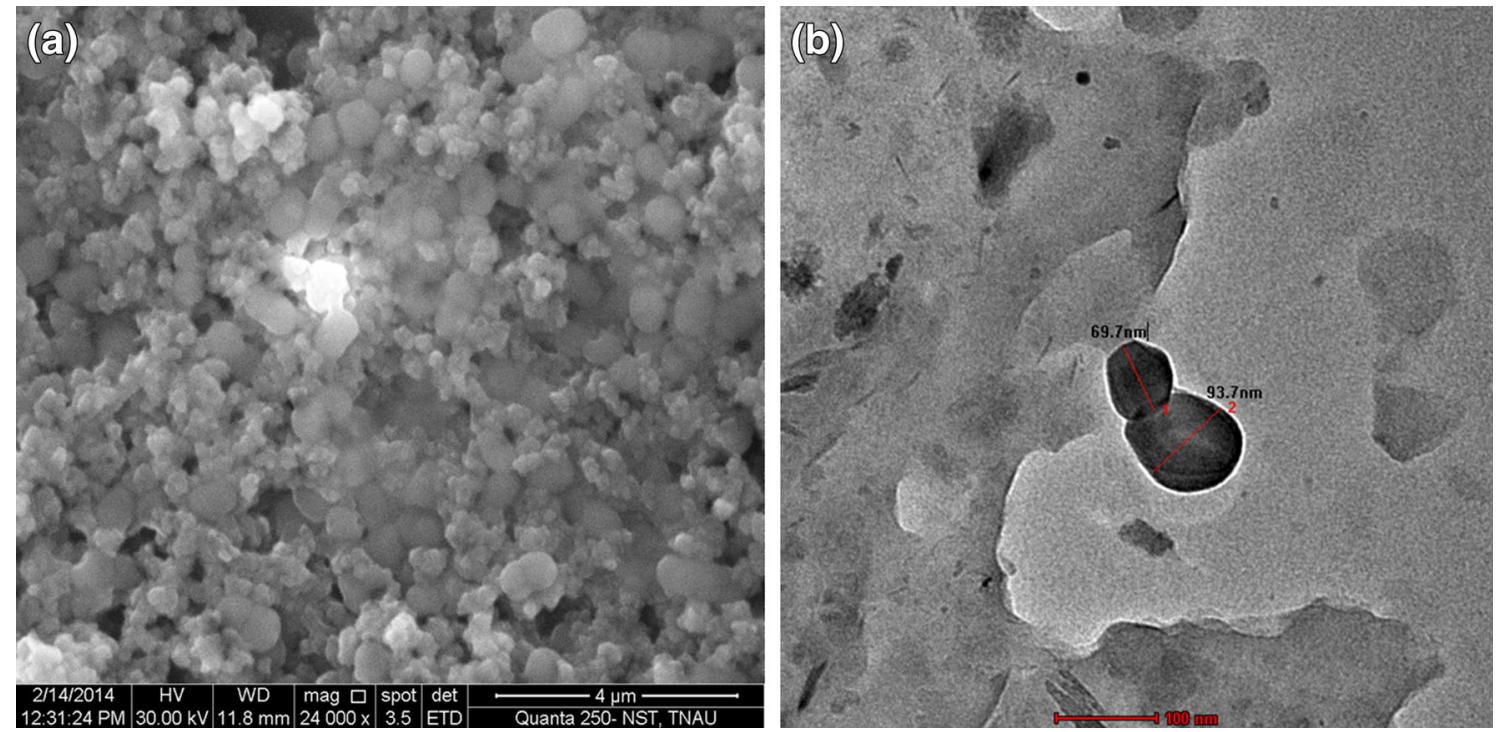

Fig. 2 a SEM. b TEM images of biosynthesized CONPs

Fig. 3 Energy dispersion spectra of synthesized CONPs with sharp elemental signal of copper

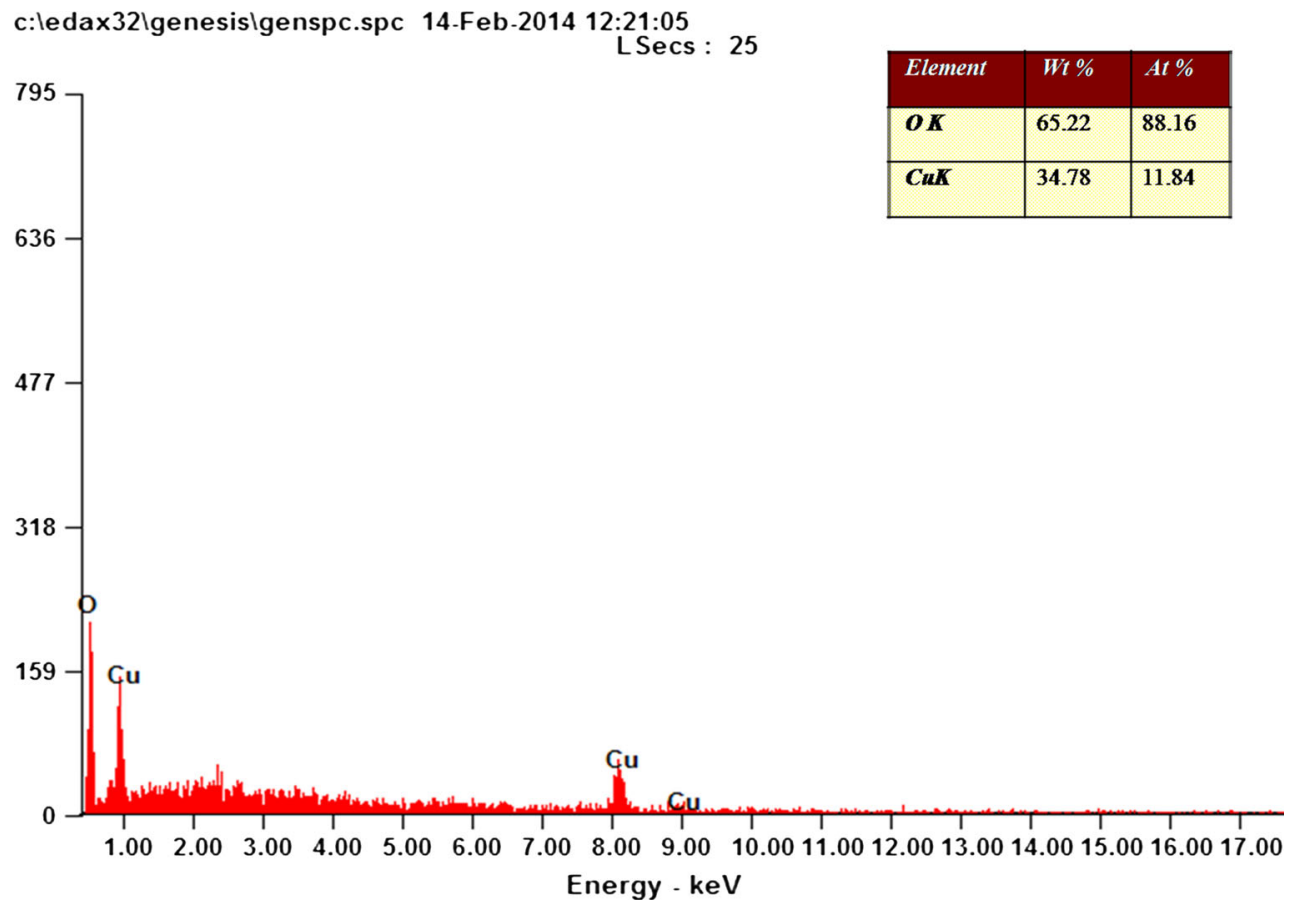




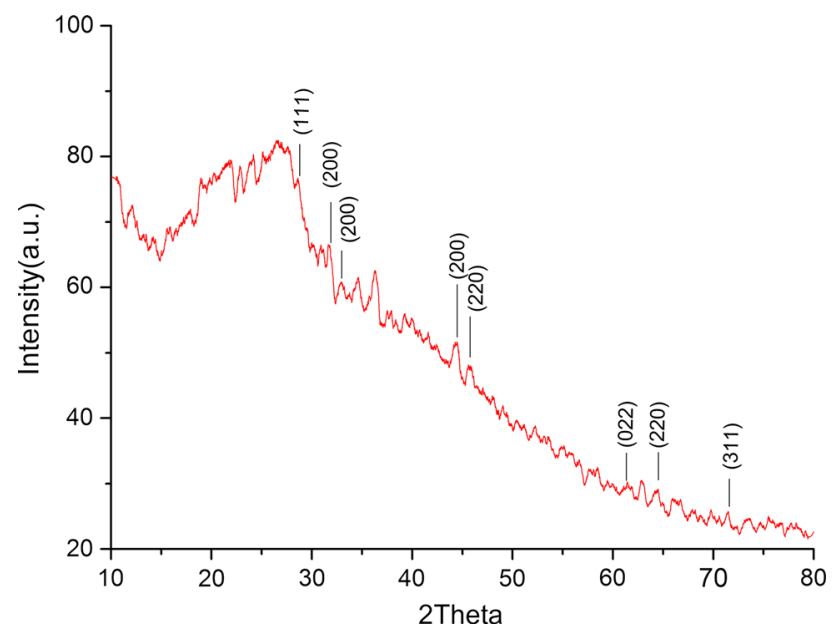

Fig. 4 Powder XRD pattern of CONPs synthesized with A. lebbeck leaf extract

Size and morphology of the CONPs were confirmed by SEM and TEM imaging analysis. The typical SEM image shown in Fig. 2a explained that the morphology of synthesized nanoparticles was observed as roughly spherical. It is evident from that the biosynthesized CONPs were observed as individual particles as well as aggregates. However, nanoparticles are not in direct contact even within the aggregates, indicating stabilization of these particles by phytochemicals present in the A. lebbeck leaf extract. The synthesized CONPs exhibited good uniformity and were mono-dispersive in nature. The monodispersivity of CONPs is a useful parameter for the biomedical applications. The size of the synthesized CONPs was characterized by TEM analysis and size was found to be lesser than $100 \mathrm{~nm}$ (Fig. 2b). The elemental composition of the biosynthesized CONPs was confirmed by EDS analysis. The EDS profile showed the presence of strong characteristic copper signal at approximately $1 \mathrm{keV}$ and oxygen signal at approximately $0.2 \mathrm{keV}$ and no other impurity peaks were observed (Fig. 3). EDS results confirmed that highly pure CONPs can be synthesized by using A. lebbeck extract and the additional peaks may be attributed due to some bioorganics present in the solution. Similar results were reported for copper nanoparticles synthesis by sublimated precursors (Soofivand and Salavati-Niasari 2013; Harne et al. 2012). Crystal structure of the nanoparticles was characterized by XRD analysis. The powder diffraction pattern of CONPs is shown in Fig. 4 and different peaks were observed at $(2 \theta)=28.63^{\circ}$, $32.08^{\circ}, 44.48^{\circ}, 46.12^{\circ}, 61.68^{\circ}, 64.52^{\circ}$ and $71.48^{\circ}$ which

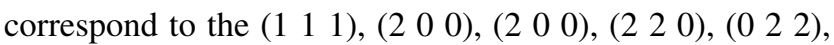
(2 200 ) and (3 111 l) lattice planes of cubic CONPs. Results of XRD spectrum indicate the presence and size of copper oxide nanoparticles are in good agreement with UV-Vis spectra and TEM image.

\section{Conclusion}

A simple method has been established for the biosynthesis of CONPs employing leaf extract of A. lebbeck. The formation of copper oxide nanoparticles was visually confirmed by the colour change followed by UV-Vis spectral characterization. SEM and TEM studies revealed the shape of synthesized nanoparticles as roughly spherical with a size range of $100 \mathrm{~nm}$. The results of this study showed that A. lebbeck leaf extract can be used as an efficient reducing agent for the facile, eco-friendly synthesis of CONPs in large scale.

Acknowledgments Authors are thankful to the Principal and Head of Industrial Biotechnology Department, Government College of Technology, Coimbatore, for their support to carry out this study. We also thank Department of Nanotechnology, Tamilnadu Agricultural University, Coimbatore, for SEM and TEM analysis.

Open Access This article is distributed under the terms of the Creative Commons Attribution License which permits any use, distribution, and reproduction in any medium, provided the original author(s) and the source are credited.

\section{References}

Abboud Y, Saffaj T, Chagraoui A, El Bouari A, Brouzi K, Tanane O, Ihssane B (2014) Biosynthesis, characterization and antimicrobial activity of copper oxide nanoparticles (CONPs) produced using brown alga extract (Bifurcaria bifurcata). Appl Nanosci 4:571-576

Abramov OV, Gedanken A, Koltypin Y, Perkas N, Perelshtein I, Joyce E, Mason TJ (2009) Pilot scale sonochemical coating of nanoparticles onto textiles to produce biocidal fabrics. Surf Coat Technol 204:718-722

Augustine R, Kalarikkal N, Thomas S (2014) A facile and rapid method for the black pepper leaf mediated green synthesis of silver nanoparticles and the antimicrobial study. Appl Nanosci 4:809-818

Baik NS, Sakai G, Miura N, Yamazoe N (2000) Preparation of stabilized nanosized tin oxide particles by hydrothermal treatment. J Am Ceram Soc 83:2983-2987

Bhattacharya D, Gupta RK (2005) Nanotechnology and potential of microorganisms. Crit Rev Biotechnol 25:199-204

Cheon J, Lee J, Kim J (2012) Inkjet printing using copper nanoparticles synthesized by electrolysis. Thin Solid Film 520:2639-2643

Dang TMD, Le TTT, Fribourg-Blanc E, Dang MC (2011) Synthesis and optical properties of copper nanoparticles prepared by a chemical reduction method. Adv Nat Sci: Nanosci Nanotechnol 2:015009

De Oliveira-Filho EC, Lopes RM, Paumgartten FJR (2004) Comparative study on the susceptibility of freshwater species to copperbased pesticides. Chemosphere 56:369-374

Gunalan S, Sivaraj R, Venckatesh R (2012) Aloe barbadensis Miller mediated green synthesis of mono-disperse copper oxide nanoparticles: optical properties. Spectrochim Acta A 97:1140-1144

Harne S, Sharma A, Dhaygude M, Joglekar S, Kodam K, Hudlikar M (2012) Novel route for rapid biosynthesis of copper nanoparticles using aqueous extract of Calotropis procera L latex and their cytotoxicity on tumor cells. Colloids Surf B 15:284-288 
Kouvaris P, Delimitis A, Zaspalis V, Papadopoulos D, Tsipas S, Michailidis N (2012) Green synthesis and characterization of silver nanoparticles produced using Arbutus unedo leaf extract. Mater Lett 76:18-20

Kruis FE, Fissan H, Peled A (1998) Synthesis of nanoparticles in the gas phase for electronic, optical and magnetic applications-a review. J Aerosol Sci 29:511-535

Lee H-J, Lee G, Jang NR, Yun JH, Song JY, Kim BS (2011) Biological synthesis of copper nanoparticles using plant extract. Nanotechnology 1:371-374

Li L, Liang J, Tao Z, Chen J (2008) CuO particles and plates: synthesis and gas-sensor application. Mater Res Bull 43:2380-2385

Mandke MV, Pathan HM (2012) Electrochemical growth of copper nanoparticles: structural and optical properties. J Electroanal Chem 686:19-24

Mie G (1908) A contribution to the optics of turbid media, especially colloidal metallic suspensions. Ann Phys 25:377-445

Mulvaney P (1996) Surface plasmon spectroscopy of nanosized metal particles. Langmuir 12:788-800

Rashmi S, Preeti V (2009) Biomimetic synthesis and characterisation of protein capped silver nanoparticles. Bioresour Technol 100:501-504

Sankar R, Manikandan P, Malarvizhi V, Fathima T, Shivashangari KS, Ravikumar V (2014) Green synthesis of colloidal copper oxide nanoparticles using Carica papaya and its application in photocatalytic dye degradation. Spectrochim Acta A 121:746-750

Soofivand F, Salavati-Niasari M (2013) Novel solvent-less synthesis of $\mathrm{CuO}$ nanoparticles by using sublimated precursors. Mater Lett 106:83-86

Tarasov S, Kolubaev A, Belyaev S, Lerner M, Tepper F (2002) Study of friction reduction by nanocopper additives to motor oil. Wear 252:63-69

Tsibakhashvil N, Kalabegishvili T, Gabunia V, Gintury E, Kuchava N, Bagdavadze N, Pataraya D, Gurielidzse M, Gvarjaladze D, Lomidze L (2010) Synthesis of silver nanoparticles using bacteria. Nano Stud 2:179-182

Vanaja M, Annadurai G (2012) Coleus aromaticus leaf extract mediated synthesis of silver nanoparticles and its bactericidal activity. Appl Nanosci 3:217-223

Vetchinkina EP, Loshchinina EA, Burov AM, Dykman LA, Nikitina VE (2014) Enzymatic formation of gold nanoparticles by submerged culture of the basidiomycete Lentinus edodes. J Biotechnol 182:37-45

Zhao Y, Zhu JJ, Hong JM, Bian N, Chen HY (2004) Microwaveinduced polyol-process synthesis of copper and copper oxide nanocrystals with controllable morphology. Eur J Inorg Chem 20:4072-4080 